\title{
IDENTIFICATION OF OCCUPATIONAL INJURY AMONG THE WORKERS OF SELECTED CEMENT INDUSTRIES IN BANGLADESH-A CASE STUDY
}

\author{
Salma A. Iqbal ${ }^{*}$, Mohammed Iqbal, Md. Zubair Taufiq and Md. Shamim Ahmed \\ Shahjalal University of Science and Technology, Sylhet, Bangladesh
}

\begin{abstract}
The paper deals with the identification of occupational injury among workers in selected cement industries of Bangladesh. In this regard, the case study was conducted to extract the overall scenario of the occupational injury. Injury data were collected by using questionnaires from the workers as well as supervisors of four cement industries. The data collected were analyzed in terms of different variables, such as body parts, agent of accident, experience, age, skill, and type of injury. Pareto analysis was then applied to find a pattern of occupational injury among the workers. The study disclosed that arm, leg, hand finger, Eye and head covered $82.81 \%$ of total injury frequency, $76.56 \%$ of total injuries by welding, bucket elevator, belt conveyor and weight lifting, low experienced and high experienced workers have 84.38\% of total injury frequency, age group of 21-25 and 51-55 have the maximum injury frequency, $78.13 \%$ injury occurred by highly skilled and unskilled workers and $79.1 \%$ of total injury is temporary disable type injury. The paper also provides specific suggestions followed by some action plans.
\end{abstract}

Keywords

injury, accident, workers, safety, cement industry and training.

\section{Introduction}

Every year throughout the world millions of industrial Every year throughout the world millions of industrial accidents occur and the world is paying heavily for accidents or injuries in terms of both human suffering and economic losses. Despite some progress, the question of safety at work is still a serious problem.

Bangladesh is a developing country. Over population, illiteracy and poverty are three major features of this country. In the industrial sector of this country, these three major features play a vital role. In maximum cases workers who start to work in industries are unskilled as they are not provided with sufficient training. These raw hands start to work as unskilled labor and through working in the practical field they become skilled as time goes on. But every year, these workers are experiencing thousands of industrial accidents which lead to different occupational injuries. These injuries have a major effect on the national economy as they cause losses of productive hours, skilled manpower, money as compensation and in addition sufferings to the victims and their family etc. Perhaps enough attention has not paid on this regard because labor is found cheap here.

*Corresponding Author's Email: siqbal-ctp@sust.edu
But this should not be the case. The workers should be provided with proper safety which will lead to reduced number of injury.

Under the above discussion it is clear that in a developing country like Bangladesh, occupational injury is a major problem which causes the economic losses in addition to the suffering of the victims.

Therefore, we have paid our interest in this field of study and have chosen "IDENTIFICATION OF OCCUPATIONAL INJURY AMONG THE WORKERS OF THE SELECTED CEMENT INDUSTRIES IN BANGLADESH" as the topic of our research work.

This work tried to show how injuries are occurred and why they occurred. It also tried to figure out the type, frequency and possible causes of injury in selected cement industries. It used the raw data found from those industries for this research work and analyzed them to find afore mentioned matters and suggested some preventive measure which would be helpful in reducing injuries.

The objectives of the research are as follows: 
- To find out different types of injuries in selected cement industries.

- To analyze the data founds in selected cement industries

Some relevant thesis works have been mentioned in this connection.

In 1974 a survey by WHO showed that in Colombia 900,000 cases of occupational accidents was reported in 1971 from among 4.5 million injured workers in 1 year. In Chile in the same year the occupational safety insurance schemes reported 74,800 disabling injuries from a population of 350,000 workers. In 1972 the corresponding number was 112,700 cases of injuries. In Bolivia in 1972 the population of 24 thousand workers in large Mines had 5430 in one year. These figures give annual rate of accidents, causing disabling injuries ranging from 21 to 34 per workers at risk [1].

In 1983, Parmeggiani L, showed in a study the causes of reported industrial accidents in the United Kingdom for the year 1978 that due to handling $25.5 \%$, persons falling $18.1 \%$, machinery $15.2 \%$, striking against object $8.1 \%$, transport $7.5 \%$, struck by falling objects $5.6 \%$, hand tools $5.8 \%$ and others $14.1 \%$ [2].

In May 2001, P J W Carrivick, A H Lee, K K W Yau published a paper on "Consultative team to assess manual handling and to reduce the risk of occupational injury", that outlines the formation of a consultative team, its recommendations on manual handling, and evaluates the team $\mathrm{s}$ effectiveness in reducing the rate and severity of workers' compensation injury within the population of hospital cleaners [3]. In 1982, the US Department of Labor published a report of 906 back injuries associated with lifting. In this study only accidents due to manual material handling were analyzed. From the data it was observed that $42 \%$ of all back injuries were due to lifting occurred in manufacturing [4]. In 1992, The National Safety Council (NSC) of America estimated that there were approximately 10,600 work related deaths in 1988, a death rate of 9 per 100,000 workers. There were 1.8 million disabling injuries on the job, of which approximately by 60,000 resulted $\mathrm{u} 1$ some permanent impairment [5]. In 1995, Johmston JJ, showed death rate from injury is the leading cause of death for people aged 1 to 44 years in the United State. Data from the National Traumatic Occupational Fatality (NTOF) surveillance system provides information on occupational fatalities for the year 1980 to 1989 by industry indicated that workers employed in the construction industry had the largest number of injuries followed by transportation, communication, and public utilities and manufacturing [6]. In Washington: November 1998. Craig Zwerling, Nancy L Spruice, Charles S Davis, Paul S Whitten published a paper on "Occupational injuries among older workers with disabilities: A prospective cohort study of the Health and Retirement Survey, 1992 to 1994", which focuses on those variables that were statistically significantly associated with occupational injury in the cross sectional analysis after control for occupation, heavy lifting, self-employment, poor hearing, and poor vision [7].

In January 1986, a publication on "Request for Assistance in Preventing Occupational Fatalities in Confined Spaces", described 16 deaths that occurred in a variety of confined spaces. If these spaces been properly evaluated prior to entry and continuously monitored while the work was being performed and if appropriate rescue procedures have been in effect, then none of the 16 deaths would have occurred [8].In December 1989, The National Institute for Occupational Safety and Health (NIOSH) Request for Assistance in Preventing Worker Deaths and Injuries from Falls Through Skylights and Roof Openings. From October 1987 through April 1989, NIOSH, as a part of the Fatal Accident Circumstances and Epidemiology (FACE) Program, has investigated five fatal falls involving skylights or roof openings. NIOSH recommends on this regard that employees who work in such places should have proper training, warning individuals against sitting or stepping on these units, manufacturers should modify the design of skylights to strengthen them sufficiently to support the weight of a worker who steps, sits, or falls on one [9].

In March 1996, Samey MH, Haque MJ, showed that in Bangladesh each year about 5000 workers are killed, injured and impaired due to accidents inside the factory shed and premises. This concerns only the factory where 10 or more workers are employed [10].

In 2000, a study was done by Dr. Zahirul to find out the pattern of occupational accident with the variables section, worker type time of occurrence, agents of accidents. This study shows that maximum accidents were minor in nature, majority of the injured cases were temporary workers and maximum accidents occurred in shift B (2 p.m.-10 p.m.), and lastly maximum accidents occurred in hands and majority of the accidents were caused by working agents [11].

In 2006, Mohammad Muhshin Aziz Khan, Mohammad Iqbal, Zaheed Ibne Halim from the department of Industrial and Production Engineering, Shahajalal University of Science and Technology, Sylhet, Bangladesh, found out the attributes of occupational injury among workers on their case study of Attributes of Occupational Injury Among Workers in the Chemical Industry and Safety Issues [12].

\section{Methodology}

The case study research was conducted in selected cement industries which are Unique Cement Industry LTD. situated at Sonargaon, Narayanganj; Meghna Cement Industry LTD. situated at Khulna; Chatak Cement Industry LTD. situated at Chatak, Cimex Cement Bangladesh LTD. situated at Mahmudnagar, Bondar, Narayanganj; in the session 2008-2009.This case study was conducted in various steps that are described in the following points.

Step 1: Primary survey :Primary survey was conducted in order to get the clear conception of the project area and to have preparation of questionnaire. Step 2: Preparing 
Primary Questionnaire:

Based on the primary survey and knowledge gathered from the literature, the questionnaires were categorized into (a) injury data collection and (b) data collection on existing safety conditions. Step 3: Verifying and Finalizing the Questionnaire: A necessary modification was made before finalizing both draft questionnaire categories followed by a group arrangement as per the objectives of the study. Step 4: Data Collection: Based on final questionnaire data were collected from the injury concerned departments like Safety department, maintenance department and management and a discussion was conducted with several workers in various different groups on the topic "Why workers are not using Personal Protective Equipment" to gather information from the workers of different level.

Based on the final questionnaire data were collected in two method which are categorized into

(a) Focus group discussion and (b) By mailing. Step 5: Data processing and analysis

At this stage the collected data were processed in tabulated form. The data that were processed represented by means of Table, Pie chart and analyzed with the help of $\mathrm{ABC}$ analysis (Pareto analysis).

\section{Data Collection and Analysis}

It is seen from table 01 given bellow, $26.56 \%$ of total injury frequency occurred in Arm and $20.31 \%$ of total injury frequency occurred in Leg.

\section{Table 1. Distribution of injury frequency by Bodily}

Location.

\begin{tabular}{|l|l|l|}
\hline Body parts & $\begin{array}{l}\text { No. of } \\
\text { injury }\end{array}$ & $\begin{array}{l}\text { Percentage of } \\
\text { injury in body } \\
\text { parts }\end{array}$ \\
\hline Arm & 17 & 26.56 \\
\hline Leg & 13 & 20.313 \\
\hline Hand finger & 9 & 14.063 \\
\hline Eye & 8 & 12.5 \\
\hline Head & 6 & 9.375 \\
\hline Shoulder & 5 & 7.813 \\
\hline Chest & 3 & 4.688 \\
\hline Back & 3 & 4.688 \\
\hline Total & 64 & $100.00 \%$ \\
\hline
\end{tabular}

The graphical representation of Table 1 is given by Pie chart. From the pie chart it is clear that Arm and Leg covers most of the area. It is clear from fig. 1 that arm, leg, hand finger, eye and head are most injured body parts and they have covered $82.81 \%$ of total injury frequency according to the Bodily Location.

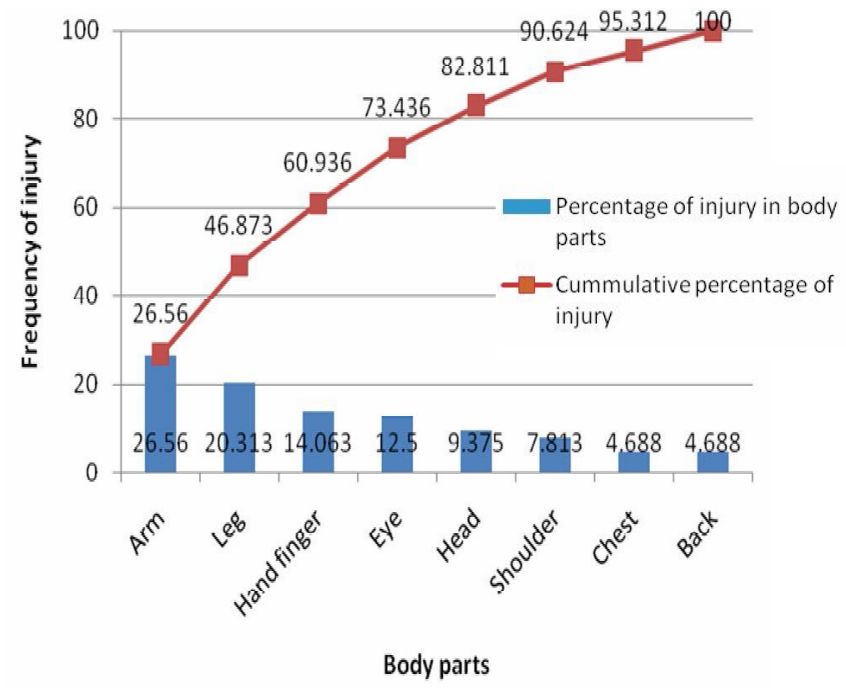

Fig 1. Pareto chart of injury frequency by body parts.

Table 2 given below shows that, $76.56 \%$ of total injuries was occurred by welding, bucket elevator, belt conveyor and weight lifting. It is also seen that highest (35.94\%) and lowest $4.69 \%$ ) injuries were caused by welding and lathe machine respectively. Pie chart helps for better understanding of Table 2.

Table 2. Distribution of injury frequency by Agent of Accident.

\begin{tabular}{|l|l|l|}
\hline Agent of Accidents & $\begin{array}{l}\text { No. of } \\
\text { injury }\end{array}$ & $\begin{array}{l}\text { Percentage of injury } \\
\text { by Agent of } \\
\text { Accidents }\end{array}$ \\
\hline Welding & 23 & 35.936 \\
\hline Belt conveyor & 10 & 15.625 \\
\hline Bucket elevator & 8 & 12.5 \\
\hline Weight lifting & 8 & 12.5 \\
\hline Struck by object & 7 & 10.938 \\
\hline Person falling & 5 & 7.813 \\
\hline Lathe machine & 3 & 4.688 \\
\hline Total & 64 & $100.00 \%$ \\
\hline
\end{tabular}

From the Pareto chart (fig 2) it is clear that most injury occurs by welding. Then followed by Belt conveyor, Bucket conveyor and Weight lifting. 


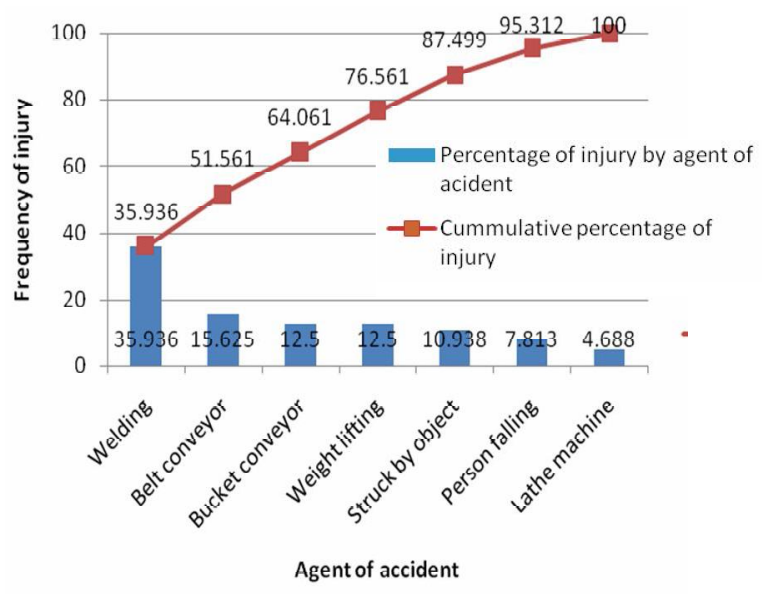

Fig 2. Pareto chart of Injury frequency by Agent of Accident.

Table 3 given below clearly shows that workers of low experience and high experience have injury frequency $56.25 \%$ and $28.13 \%$ respectively. So it is clear that worker having low experience and high experience have $84.38 \%$ of total injury frequency.

Table 3. Distribution of injury frequency among different Experience level of workers.

\begin{tabular}{|l|l|l|}
\hline Experience & $\begin{array}{l}\text { No. of } \\
\text { injury }\end{array}$ & $\begin{array}{l}\text { Percentage of injury } \\
\text { among different } \\
\text { Experience level }\end{array}$ \\
\hline $\begin{array}{l}\text { Low experienced } \\
\text { (0-2 years) }\end{array}$ & 36 & 56.25 \\
\hline $\begin{array}{l}\text { High experienced } \\
\text { (Above 5 years) }\end{array}$ & 18 & 28.125 \\
\hline $\begin{array}{l}\text { Medium } \\
\text { experienced (2-5 } \\
\text { years })\end{array}$ & 10 & 15.625 \\
\hline Total & 64 & $100.00 \%$ \\
\hline
\end{tabular}

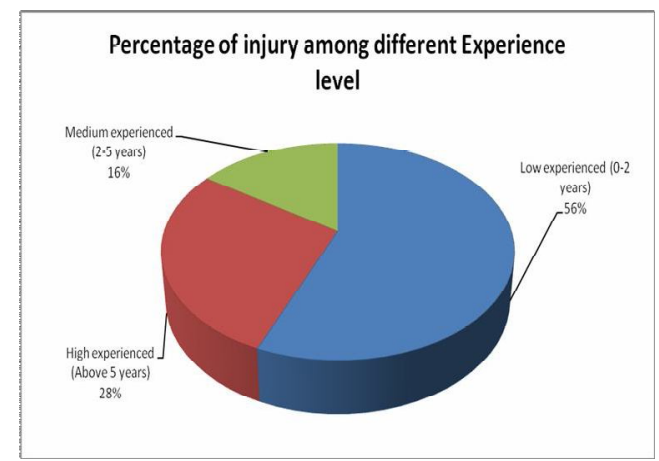

Fig 3. Pie chart of injury frequency among different Experience level of workers.

Here the vital few, in which experience level faced the injury most are Low experienced and high experienced.

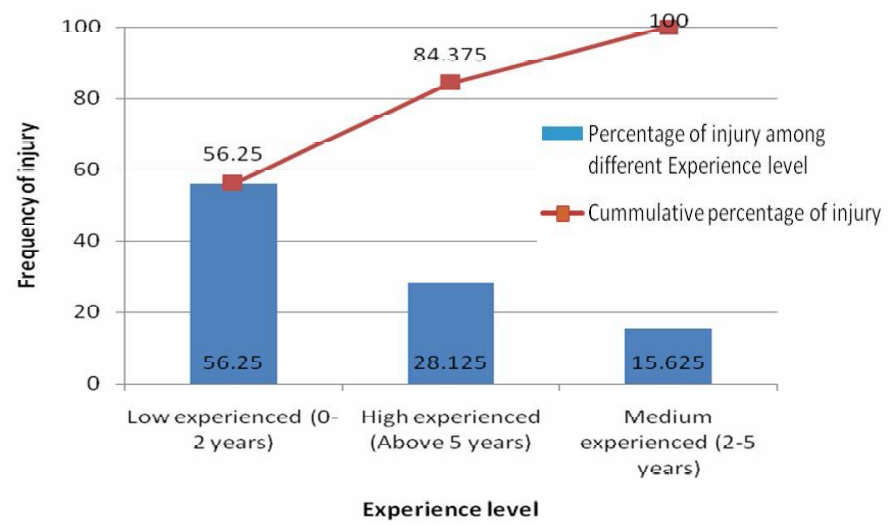

Fig 4. Pareto chart of injury frequency among different experience level of workers.

Table 4 presented below shows that workers of 21-25 and $51-55$ age groups have the injury frequency $23.44 \%$ and $29.69 \%$ respectively.

Table 4. Distribution of injury by age groups.

\begin{tabular}{|l|l|l|}
\hline $\begin{array}{l}\text { Age } \\
\text { group }\end{array}$ & $\begin{array}{l}\text { No. of } \\
\text { injury }\end{array}$ & $\begin{array}{l}\text { Percentage of injury } \\
\text { among different Age } \\
\text { group }\end{array}$ \\
\hline $51-55$ & 19 & 29.687 \\
\hline $21-25$ & 15 & 23.437 \\
\hline $46-50$ & 7 & 10.938 \\
\hline $36-40$ & 7 & 10.938 \\
\hline $41-45$ & 6 & 9.375 \\
\hline $26-30$ & 6 & \\
\hline $26-30$ & 6 & 9.375 \\
\hline $31-35$ & 4 & 6.25 \\
\hline Total & 64 & $100.00 \%$ \\
\hline
\end{tabular}

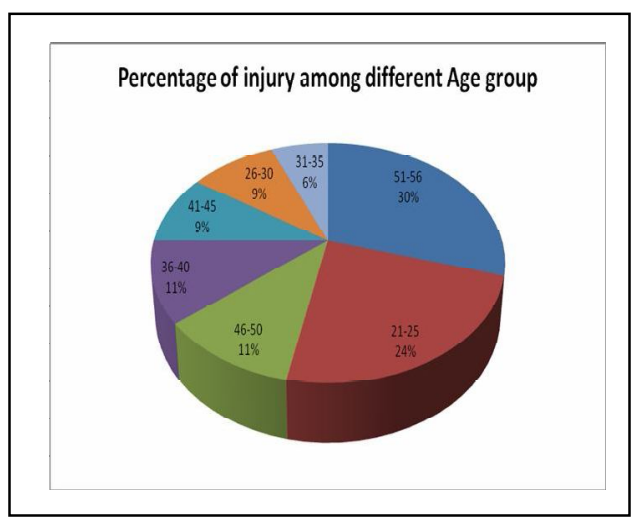

Fig 5. Pie chart of injury frequency by Age Groups. 
From the Pie chart (fig. 5) it is clear that the highest covered area in this chart are by Age group of 51-55, 2125, 46-50. From the Pareto chart (fig. 6) it is clear that workers having age of below 25 years and above 50 years had an injury frequency of $53.13 \%$ of the total injury that occurred in different age groups.

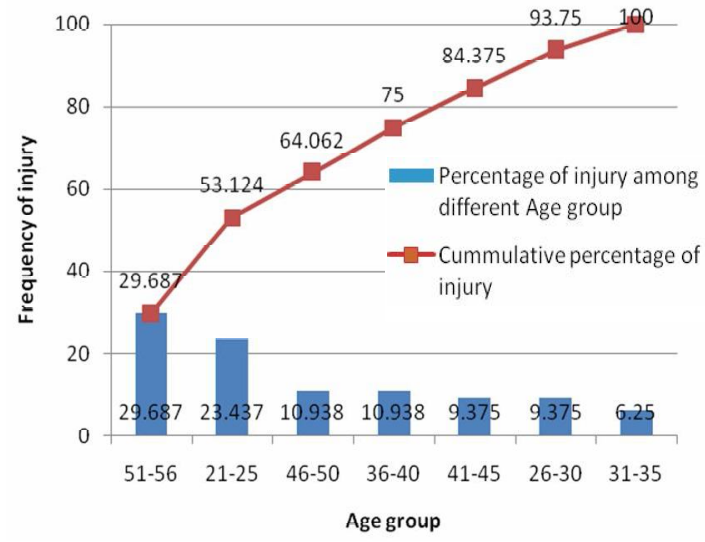

Fig 6. Pareto chart of Injury frequency by Age Group.

Table 5. Distribution of injury among different level of skilled workers.

\begin{tabular}{|l|l|l|}
\hline Skill ness & $\begin{array}{l}\text { No. of } \\
\text { injury }\end{array}$ & $\begin{array}{l}\text { Percentage of injury } \\
\text { among different level of } \\
\text { skilled worker }\end{array}$ \\
\hline Unskilled & 35 & 54.688 \\
\hline High skilled & 15 & 23.437 \\
\hline Skilled & 8 & 12.5 \\
\hline Semi skill & 6 & 9.375 \\
\hline Total & 64 & $100.00 \%$ \\
\hline
\end{tabular}

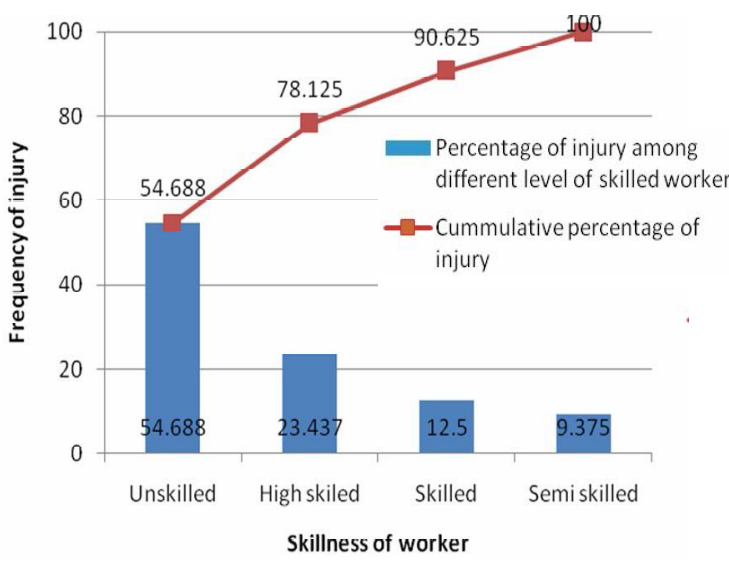

Fig 7. Pareto chart of injury frequency among different level of skilled workers.

Table 5 shows that most $35.94 \%$ injured workers were skilled; among them $23.44 \%$ and $12.50 \%$ were highly skilled and skilled workers respectively. It is worth mentioning that most $54.69 \%$ injured workers were unskilled.

Here the Unskilled worker covered the most area.

From Figure 7, it is evident that highly skilled and unskilled workers accounted for around $78.13 \%$ of the total number of injured workers.

Table 6 shows that $79.1 \%$ of total injury is temporary disable type injury. Thus it proves that in cement industries the rate of death is very low.

Table 6. Distribution of injury by different types of injury.

\begin{tabular}{|l|l|l|}
\hline Types of injury & $\begin{array}{l}\text { No. of } \\
\text { injury }\end{array}$ & $\begin{array}{l}\text { Percentage of injury } \\
\text { by types of injury }\end{array}$ \\
\hline $\begin{array}{l}\text { Temporary } \\
\text { disability }\end{array}$ & 53 & 79.1 \\
\hline Total disability & 11 & 16.42 \\
\hline Death & 3 & 4.48 \\
\hline Total & 67 & $100.00 \%$ \\
\hline
\end{tabular}

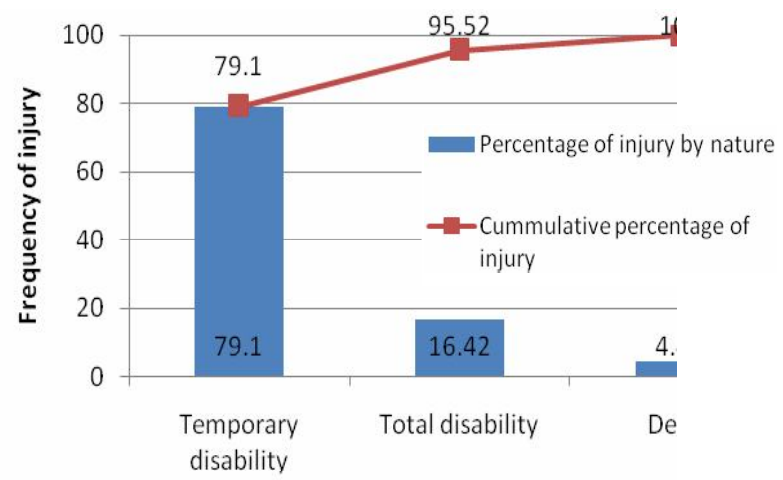

Nature of injury

Fig 8. Pareto chart of injury frequency by different types of injury.

From Fig. 8 it is seen that temporary disable is maximum (79.1\%) and total disability is less than temporary disable .

\section{Findings and Results}

From the analysis applied to the distributed data, some important points show up very significantly.

In process-based industry comparatively older workers, especially those above the age of 50 were responsible for the occupational injury that occurred. These aged workers naturally landed with improper physical capabilities and Pareto analysis statistically proved this fact. 
Pareto analysis revealed that arm, leg, hand finger and eye were the body parts that were mostly injured. The relation between agents of accident and those body parts could explain the statistics. Highly skilled and unskilled workers were found to be responsible for occupational injuries. A very frustrating reason for this was the overconfidence of unskilled and highly skilled workers.

Welding, bucket elevator and belt conveyor were the vital few that contribute to occupational injury statistics. Basically these agents were the reason for injuries to the major body parts.

Inexperienced and highly experienced workers were found to be responsible for occupational injuries. The reason behind these is also overconfidence of highly experienced workers and inadequate training for inexperienced workers.

Frequencies of death or fatal injury in cement industries are very low. Most of the injuries are temporary disable type of injury.

As it was already mentioned, several agents of accident caused injuries in the major body parts of the workers. This was obviously because of overconfidence and lack of awareness. In a word, lack of awareness and responsibility in both the authorities and workers could make this sort of injury very frequent.

Occupational injury is a serious problem in any industry. These injuries directly affect the productivity of the industry because injuries lead to loss of productive hour along with loss of money as compensation. To reduce occupational injury some planned measures is to be taken. Next section represents the recommendation and action to be taken for the best implementation of the recommendation for injury reduction.

\section{Recommendations}

In the light of the analysis and overall findings this study recommends a few steps and action planning which if implemented carefully and efficiently in the concerned organizations the frequency of injury might have been reduced considerably about $70 \%$ to $80 \%$. The recommendations are:

(a)Regular medical check up on hearing, sight and strength of workers aged 45 years and above. Leisure during working period for workers to reduce fatigue and bore ness(c) Sufficient training for workers on safe operation of welding, conveyor, lathe and different machines or works they are engaged in like Carrying \& Lifting (e)Proper safe guards to the agents of accidents like bucket elevator, belt conveyor, welding, carrying and lifting etc.(f)Adequate supply and regular cleaning of personal protective equipment.(g)Ensuring proper use of personal protective equipment for all workers.(h)Ensuring the use of gloves, musk and shoes during working on factory and for Carrying \& Lifting, helmets during working on bucket elevator, goggles and face shields while working on welding, gloves for handling chemicals and raw materials.

\section{Action Plans}

The proper and efficient functioning of the recommendation depends on some sequential action which is called here action plans. The actions planning for the recommendation of this work are pointed below:

1) The adequate supply of Personal Protective Equipment with proper condition would not be sufficient for eliminating the causes of not using Personal Protective Equipment unless the organization take the following actions:

(a) Adequate training on safety (b)Motivating the workers for using Personal (c)Protective Equipment (d)Growing awareness among the workers by using safety signs, tags and periodic group discussion on safety (e)Regular supervision regarding safety.

2) As all the organizations considered in this study are process industry, leisure for any shift for all workers at a time is not possible without interrupting or shutting down the whole process. So the workers can be divided into different groups. A group may consist of workers from different departments in such a way that the production process will not be affected. Then leisure can be provided in different times during working period for one or two groups at a time. Then the production process will not be affected. Leisure of 10 minutes after two hours is suitable for light work [18].

3) Ensuring the use of proper personal protective equipment for working on welding and bucket elevator, proper fencing while working on belt conveyor.

4) Perfect carrying and lifting techniques for heavy loads.

Implementation of the recommendations and action planning can reduce the occupational injury in these selected industries.

\section{Conclusion}

This study has been conducted taking some variables into considerations with a view to get an overall picture of occupational injury among workers and to enhance safety conditions of the Cement industries that are studied. While conducting the study, it was found that workers aged over 50 were more exposed to injury; arm, leg, hand finger and eye were the most affected body parts. Most of the injured people were highly skilled and unskilled workers; Welding, bucket elevator and belt conveyor caused most of the injuries. It is also worth mentioning that an insufficient supply of Personal Protective Equipment, poorly maintained Personal Protective Equipment, discomfort when using Personal Protective Equipment and overconfidence were found to be the major causes of injury; whereas lack of awareness and carelessness was indicated as minor causes for not using Personal Protective Equipment. However, to keep workers safe and sound physically as well as 
economically and to prevent loss of production time causing loss to employers, preventive actions recommended should be implemented and maintained carefully and sincerely.

\section{References}

1. DGHS and WHO : Industrial Hygine Unit DGHS, Occupational Health and Safety (1995), Bangladesh.

2. Parmeggiani, L (eds.) (1983), Encyclopedia of Occupational Health and Safety. 3rd edition, GENEVA, ILO, 1167.

3. Occupational and Environmental Medicine, Vol. 58, Issue.5, 339.

4. Helander, M., A Guide to the Ergonomics of Manufacturing, 39.

5. Skorrn M. L. (1992), Epidemiology of Occupational Injury.In: Rom, W.N. Environmental and Ocupational Medicine, 2nd edition. London, Little, Brown \& Company Publishers, 725.

6. Johmston J.J. (Oct, 1995), Occupation Injury and Stress, JOEM, 37.
7. American Journal of Public Health (Nov 1998), Washington, Vol. 88, Iss. 11, 1691.

8. DHHS (NIOSH) Publication No. 86-110.

9. NIOSH ALERT (December 1989), DHHS (NIOSH) Publication No. 90-100.

10. Samey, M. H. and Haque M.J. (March 1996), Pattern of accidental death in Rangpur medical college morgue, Northern Medical Journal, $20 \& 21$

11. Haq, Z. (2000-2001), Attributes of Occupational Accidents among Workers of Three Selected Jute mills, 5 .

12. Khan, M. M. A., Iqbal, M. and Halim, Z. I. (2006), Attributes of Occupational Injury Among Workers in the Chemical Industry and Safety Issues, International Journal of Occupational Safety and Ergonomics (JOSE), Vol. 12, No. 3, 327-341. 